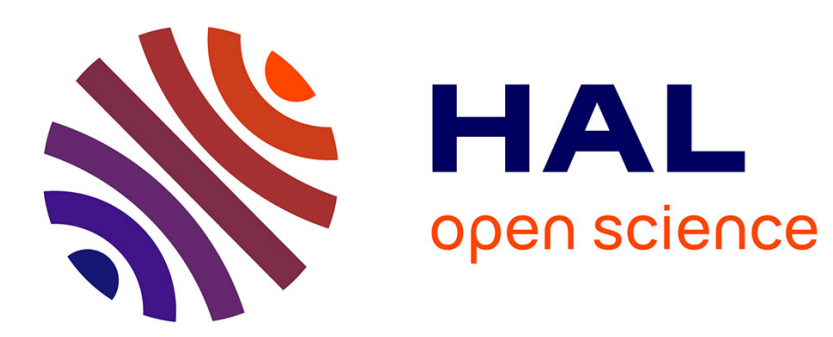

\title{
Multivariate VaRs for Operational Risk Capital Computation: a Vine Structure Approach
}

\author{
Dominique Guegan, Bertrand Hassani
}

\section{To cite this version:}

Dominique Guegan, Bertrand Hassani. Multivariate VaRs for Operational Risk Capital Computation: a Vine Structure Approach. 2012. halshs-00587706v3

\section{HAL Id: halshs-00587706 \\ https://shs.hal.science/halshs-00587706v3}

Submitted on 17 Jul 2012

HAL is a multi-disciplinary open access archive for the deposit and dissemination of scientific research documents, whether they are published or not. The documents may come from teaching and research institutions in France or abroad, or from public or private research centers.
L'archive ouverte pluridisciplinaire HAL, est destinée au dépôt et à la diffusion de documents scientifiques de niveau recherche, publiés ou non, émanant des établissements d'enseignement et de recherche français ou étrangers, des laboratoires publics ou privés. 


\section{Documents de Travail du Centre d'Economie de la Sorbonne}

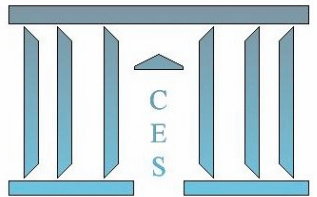

\section{Multivariate VaRs for Operational Risk Capital \\ Computation : a Vine Structure Approach}

Dominique GUEGAN, Bertrand HASSANI

2011.17

Version révisée

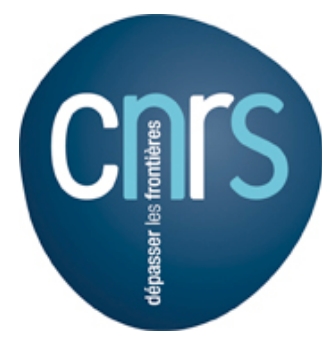




\title{
Multivariate VaRs for Operational Risk Capital Computation: a Vine Structure Approach
}

\author{
April 25, 2012
}

\section{Authors}

- Dominique Guégan: Université Paris 1 Panthéon-Sorbonne, CES UMR 8174, 106 boulevard de l'Hopital 75647 Paris Cedex 13, France, phone: +33144078298, e-mail: dguegan@univparis1.fr

- Bertrand K. Hassani: AON and Université Paris 1 Panthéon-Sorbonne CES UMR 8174, 8 Devonshire Square, EC2M 4PM London, United Kingdom, phone: +44 (0)2070860973, e-mail: bertrand.hassani@aon.co.uk 


\begin{abstract}
The Basel Advanced Measurement Approach requires financial institutions to compute capital requirements on internal data sets. In this paper we introduce a new methodology permitting capital requirements to take into account the embedded dependence structures of operational risks. The loss distributions are provided in a matrix of 56 cells. Constructing a vine architecture, which is a bivariate decomposition of a $n$-dimensional structure $(n>2)$, we use this approach to compute multivariate operational risk VaRs. We analyse the results and compare them with classical methodologies based on LDF modelings. Our method is simple to carry out, easy to interpret and complies with the new Basel Committee requirements.
\end{abstract}

Keywords: Operational risks - Vine Copula - Loss Distribution Function - Nested Structure - VaR 


\section{Introduction}

The Basel Committee advanced approaches oblige banks to carry out internal model to evaluate the amounts of capital needed to face their risks (BCBS (2004)). In terms of operational risks, the proposals are still in their infancy, and most banks' internal strategies are based on traditional models whose assumptions are not always realistic. It may often be observed that risk managers' teams use very simple or naive methodologies although the operational risks are intrinsically complex. Indeed, to compute capital allocations, two sets of information characterized by different statistical distributions need to be considered. These represent the frequencies and the severities. The presence of correlation and dependencies between severities and/or frequencies have been highlighted by Chernobai et al. (2007). The dependencies must be taken into account in the model design. As the model is more sensitive to the severities than to the frequencies, the current paper focuses on the dependencies between severities and uses them to derive the overall capital allocation.

In order to comply with Basel II requirements, we propose a novel approach based on recent methodologies to associate a risk measure (e.g. the Value-at-Risk (VaR) (Jorion (2006))) with the risk profile of a financial institution. Following the Basel Matrix risk classification, we provide an original way to obtain this VaR associated with a medium-sized set of operational risk categories $(>3)$ based on the copula methodology. A robust way to measure the dependence between large data sets is to compute their joint distribution function by using copula tools. Indeed, a copula is a multivariate distribution function linking a large set of data through their standard uniform marginal distributions (Sklar (1959), Nelsen (2006)). In the literature, it has often been mentioned that the use of copulas is difficult in high dimensions apart from when one uses an elliptic structure (Gaussian or Student) (Di Clemente and Romano (2004)). In this paper we release these restrictions by considering recent developments on copulas: nested copulas (Morillas (2005), Savu and Trede (2006)) and vine copulas (Aas et al. (2009), Berg and Aas (2009), Guégan and Maugis (2010), Brechmann et al. (2010) and Dissmann et al. (2011)).

These $n$-dimensional copulas need to be fed by some marginal distributions. In our case they correspond to the Loss Distribution Function (LDF). As a huge literature for the choice of 
severities and frequency distributions (Cruz (2004)) already exists, we will not go any further in details. Thus, in the following we restrict our analysis to the Poisson distribution for the frequency distribution ${ }^{1}$ and, for the severity distribution, we consider the empirical, the lognormal, the Gumbel and the Generalized Pareto distributions. In our application we show that the calibration of the severity function plays an important role in the computation of the risks, whatever the method used for the dependence structure. Our results confirm previous facts already stated in the literature (Gourier et al. (2009), Guégan et al. (2011), etc.) but the new methodology used here permits the detection of specific behavior useful for risk management, such as the upper tail dependence of the severities.

In a first step, we estimate the severity distributions for each cell of the Basel Matrix (Table 1). In a second step we focus on the choice of the copulas to measure the dependence between these cells. We use the empirical severity distribution to estimate the parameters of the chosen dependence structure, and then we apply this to the LDFs. As soon as we consider higher dimensions, we face some problems. Traditionally, practitioners use Gaussian or Student's t copulas. However, as these one are belonging to the elliptic family, they fail to capture asymmetric shocks (by definition operational risks severity distributions are asymmetric). For example, using a Student copula with three degrees of freedom ${ }^{2}$ to capture a dependence between the largest losses, would also induce a higher correlation between the very low losses. An alternative is found in Archimedean copulas (Joe (1997)) which have attracted particular interest due to their capability to capture the dependence embedded in different parts of the marginal distributions (right tail, left tail and body). Nevertheless as soon as we want to measure a dependence between more than two sets, the use of this class of copulas becomes limited as they are generally driven by a single parameter. Therefore traditional estimation methods may fail to capture the dependence intensity. Therefore, a large number of multivariate Archimedean structures have been developed, for instance the fully nested structures, the partially nested copulas and the hierarchical ones. Nevertheless, all these architectures imply restrictions on the parameters and impose using an Archimedean copula at each node making their use limited in practice, for instance the Archimax

\footnotetext{
${ }^{1}$ Trough our analysis, we tested different other distributions such a the binomial and the negative binomial to model the frequencies and as we have not noticed any sensitivity of the capital charge to these ones, we only used the Poisson distribution.

${ }^{2} \mathrm{~A}$ low number of degrees of freedom imply a higher dependence in the tail of the marginal distributions
} 
copulas (Capéraà et al. (2000)) which include non-symmetric extreme-value copulas introduced by Gudendorf and Segers (2010). Thus in our application we do not focus on this class of copulas.

To bypass the restrictions imposed by the previous nested strategy, we use an intuitive approach proposed by Joe (1996), based on a pair-copula decomposition. We limit our analysis to the so-called D-vine (Kurowicka and Cooke (2004)) in which no node in the structure is connected to more than two edges (Aas et al. (2009)). This approach rewrites the $n$-density function associated with the $n$-copula, as a product of conditional marginal and copula densities. We build iteratively all the conditioning pair densities to get the final one representing the entire dependence structure. The approach is simple, and has no restriction for the choice of functions and their parameters. Its only limitation is the number of decompositions we have to consider as the number of vines grows exponentially with the dimension of the data sample and thus requires the user to select a vine from $\frac{n !}{2}$ possible vines. The optimal strategy to employ is not considered in this paper. We instead refer the interested reader to Antoch and Hanousek (2000), Bedford and Cooke (2002), Brechmann et al. (2010) and Guégan and Maugis (2011).

To summarize, our strategy not only consists in computing a global capital charge for the financial institution considered, but also in obtaining the standalone contribution of each marginal distribution to the global capital requirement, which is the most interesting topic for risk managers as it enables them to identify the business units which need particular attention. Indeed, practitioners need to understand which processes engender the largest marginal capital and why.

The paper is organized as follows. In Section 2, we introduce and detail the methodology and the computation of the dependence structure for the Basel Matrix given in Table 1. In Section 3 , we present our experimental process and we provide the corresponding capital requirement by lines, columns and for the whole matrix. Section 4 addresses some practical issues. Section 5 concludes. 


\section{A High Dimensional Structure for Operational Risk}

In order to leave the elliptical domain to obtain another dependence measure for large data sets, new $n$-dimensional dependence structures have been proposed in the literature: the nested structures and the pair-copula structures called vine copulas. Nested and pair-copula architectures are based on successive bivariate copula decompositions. Nested copulas based on Archimedean nodes were originally introduced by Joe (1997), have been studied by Morillas (2005), Savu and Trede (2006) and applied by Aas et al. (2009) and Berg and Aas (2009). They can be divided in four types: exchangeable nested copulas, fully nested copulas, partially nested copulas and hierarchically nested copulas. The first class imposes very restrictive dependence structures on the copulas as soon as the number of nodes increases: the $m$-dimensional marginal distributions $(m<n)$ and the generators need to be identical. The three other classes which are extensions of the first structure are more flexible. Nevertheless they are all constrained by the choice of the copula parameter whose value has to decrease as soon as the level of nodes increases.

In Figure 1, we illustrate the fully nested copulas in a 4-dimensional case. The initial level is composed of univariate distributions, the second level presents the copula considering onedimensional marginals, the third level is built with a copula linking the previous copula and an univariate distribution, and so on. In Figure 2 we illustrate the partially nested copula. The initial level is composed of distributions representing each Basel category for instance, the second level represents the copulas linking these marginal distributions and the third level corresponds to the copula linking the two previous ones. The nested architecture which is a very interesting concept in theory is based on assumptions that are too limited to be used in practice. Paircopula architectures (Figure 3), suggested by Joe (1996) are more flexible: any class of copula can be used, and no restriction is required on the parameters. Nevertheless, compared to nested structures, vine copulas require testing and estimating a large quantity of copulas.

To be more accurate the formal representation of copulas is defined in the following way. Let $X=\left[X_{1}, X_{2}, \ldots, X_{n}\right]$ be a vector of random variables, with joint distribution $F$ and marginal distributions $F_{1}, F_{2}, \ldots, F_{n}$, then Sklar (1959) theorem insures the existence of a function $C$ 
mapping the individual distributions $F_{1}, \ldots, F_{n}$ to the joint one $F$ :

$$
F(x)=C\left(F_{1}\left(x_{1}\right), F_{2}\left(x_{2}\right), \ldots, F_{n}\left(x_{n}\right)\right)
$$

where $x=\left(x_{1}, x_{2}, \ldots, x_{n}\right)$. we call $C$ a copula.

The Archimedean nested type is the most intuitive way to build $n$-variate copulas with bivariate copulas, and consists in composing copulas together, yielding formulas of the following type for $n=3:$

$$
\begin{aligned}
F\left(x_{1}, x_{2}, x_{3}\right) & =C_{\theta_{1}, \theta_{2}}\left(F\left(x_{1}\right), F\left(x_{2}\right), F\left(x_{3}\right)\right) \\
& =C_{\theta_{1}}\left(C_{\theta_{2}}\left(F\left(x_{1}\right), F\left(x_{2}\right)\right), F\left(x_{3}\right)\right)
\end{aligned}
$$

where $\theta_{i}, i=1,2$ is the parameter of the copula. This decomposition can be done several times, allowing to build copulas of any dimension under specific constraints.

To present the vine copula method, we use here for simplicity its representation through the density decomposition and not the distribution function as before. Denoting $f$ the density function associated with the distribution $F$, then the joint $n$-variate density can be obtained as a product of conditional densities. For $n=3$, we have the following decomposition:

$$
f\left(x_{1}, x_{2}, x_{3}\right)=f\left(x_{1}\right) \cdot f\left(x_{2} \mid x_{1}\right) \cdot f\left(x_{3} \mid x_{1}, x_{2}\right),
$$

where

$$
f\left(x_{2} \mid x_{1}\right)=c_{1,2}\left(F\left(x_{1}\right), F\left(x_{2}\right)\right) \cdot f\left(x_{2}\right),
$$

and $c_{1,2}\left(F\left(x_{1}\right), F\left(x_{2}\right)\right)$ is the density copula associated with the copula $C$ which links the two marginal distributions $F\left(x_{1}\right)$ and $F\left(x_{2}\right)$. With the same notations we have:

$$
\begin{aligned}
f\left(x_{3} \mid x_{1}, x_{2}\right) & =c_{2,3 \mid 1}\left(F\left(x_{2} \mid x_{1}\right), F\left(x_{3} \mid x_{1}\right)\right) \cdot f\left(x_{3} \mid x_{1}\right) \\
& =c_{2,3 \mid 1}\left(F\left(x_{2} \mid x_{1}\right), F\left(x_{3} \mid x_{1}\right)\right) \cdot c_{1,3}\left(F\left(x_{1}\right), F\left(x_{3}\right)\right) \cdot f\left(x_{3}\right) .
\end{aligned}
$$

Then,

$$
\begin{aligned}
f\left(x_{1}, x_{2}, x_{3}\right)= & f\left(x_{1}\right) \cdot f\left(x_{2}\right) \cdot f\left(x_{3}\right) \\
& . c_{1,2}\left(F\left(x_{1}\right), F\left(x_{2}\right)\right) \cdot c_{1,3}\left(F\left(x_{1}\right), F\left(x_{3}\right)\right) \\
& . c_{2,3 \mid 1}\left(F\left(x_{2} \mid x_{1}\right), F\left(x_{3} \mid x_{1}\right)\right) .
\end{aligned}
$$


That last formula is called vine decomposition. Many other decompositions are possible using different permutations. Details can be found in Berg and Aas (2009), Guégan and Maugis (2010) and Dissmann et al. (2011).

In the applications below, we focus on these vine copulas and in particular the D-vine whose density $f\left(x_{1}, \ldots, x_{n}\right)$ may be written as,

$$
\prod_{k=1}^{n} f\left(x_{k}\right) \prod_{j=1}^{n-1} \prod_{i=1}^{n-j} c_{\theta, i, i+j \mid i+1, \ldots, i+j-1}\left(F\left(x_{i} \mid x_{i+1}, \ldots, x_{i+j-1}\right), F\left(x_{i+j} \mid x_{i+1}, \ldots, x_{i+j-1}\right)\right)
$$

where index $j$ identifies the trees, while $i$ runs over the edges in each tree.

To our knowledge such a methodology has never been used to associate a risk measure with operational risks, and it is new comparing to the works of Di Clemente and Romano (2004) and Gourier et al. (2009) for instance.

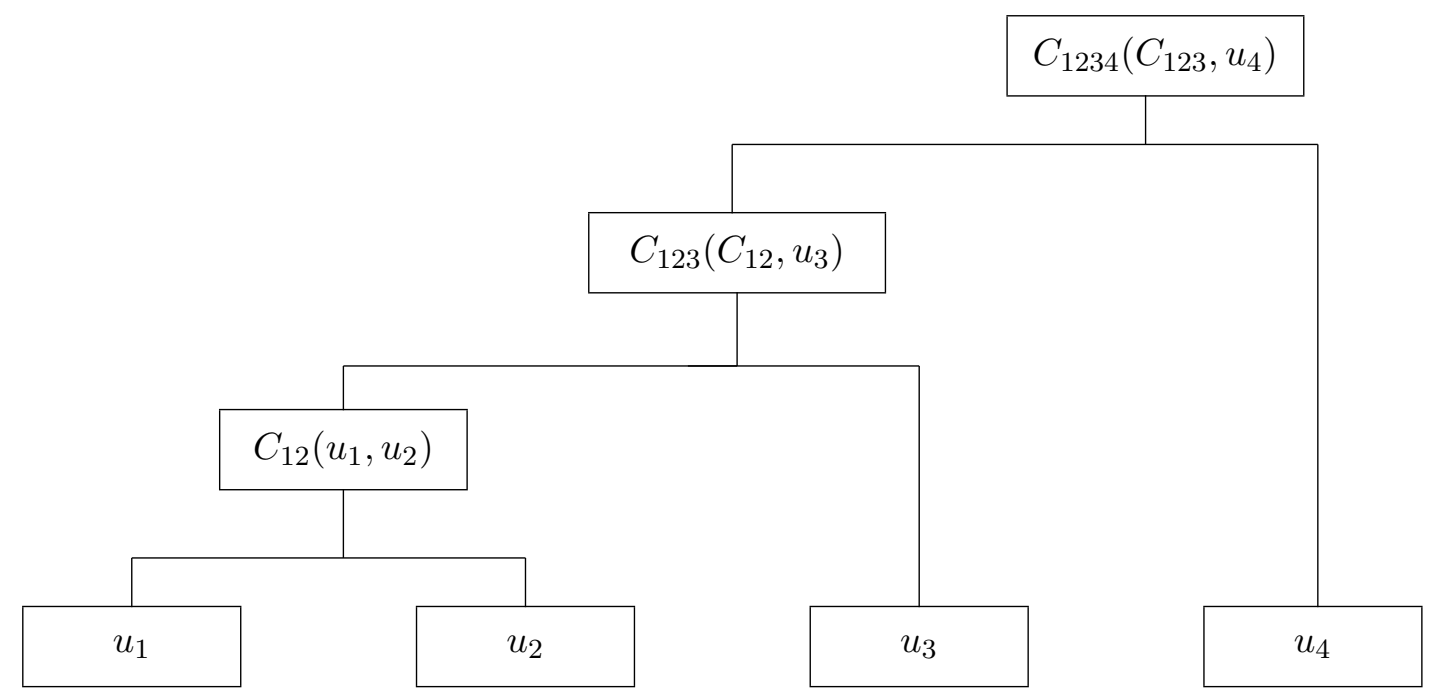

Figure 1: Fully Nested Copula illustration 


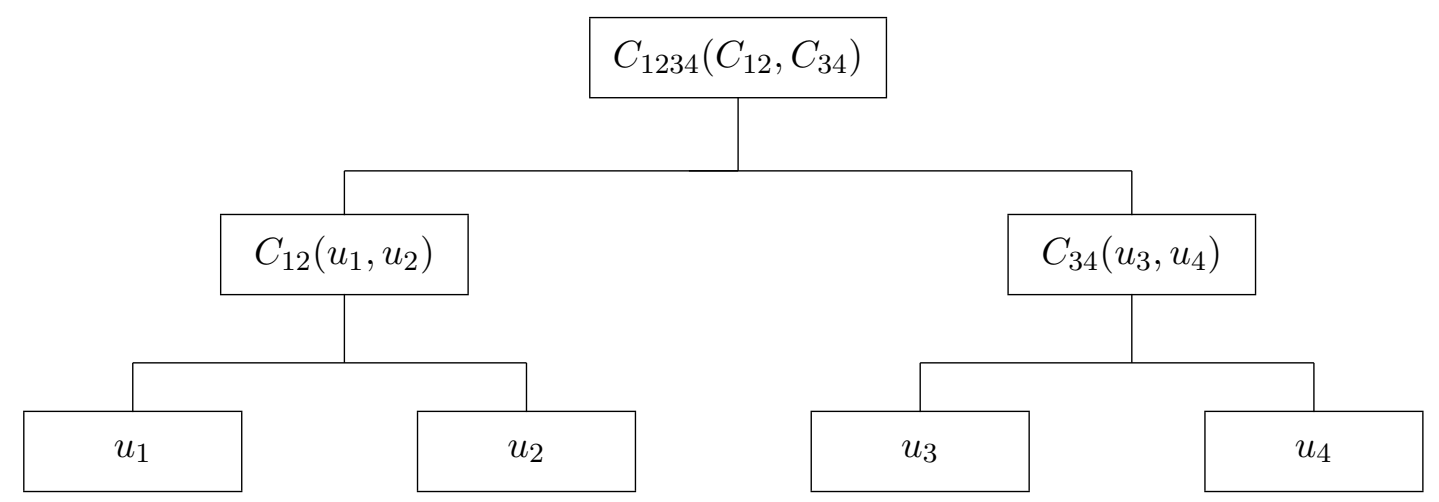

Figure 2: Partially Nested Copula illustration

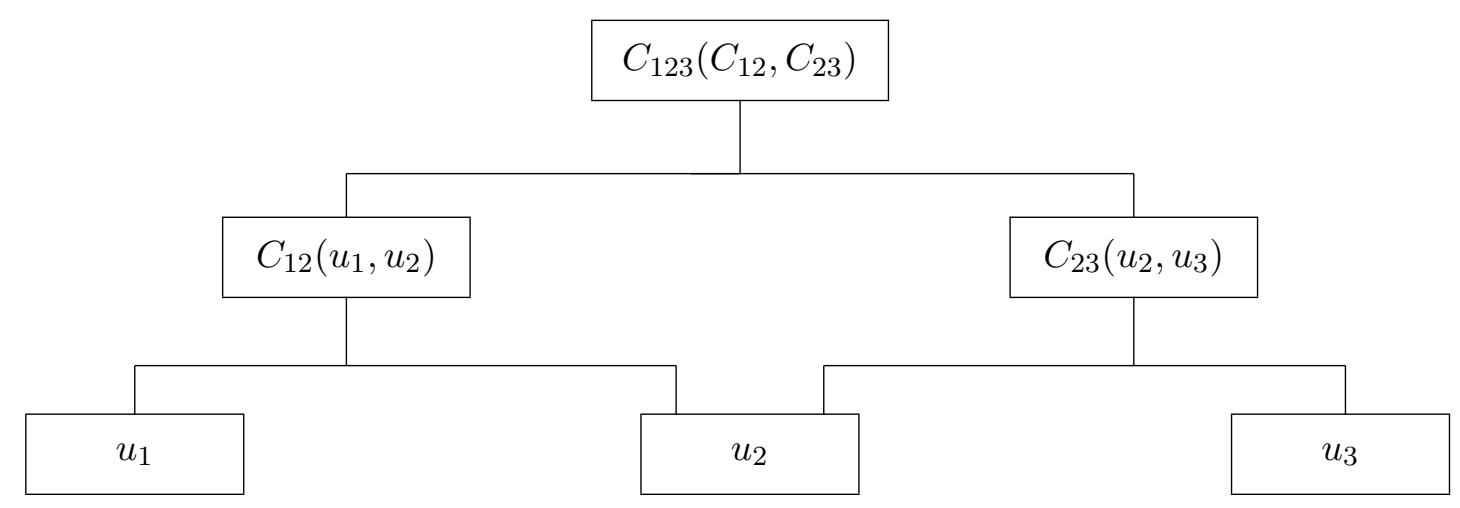

Figure 3: 3-dimensional D-vine illustration: it represents another kind of structure we could have considering a decomposition similar to 2.1, considering the cdfs.

\section{Results}

The estimation part and the computation of the capital requirement for the Basel matrix is now detailed. 


\subsection{Experimental Process}

The methodology developed in this paper is applied to the Basel Matrix (BCBS (2001)) given in Table 1. This Table is composed of 56 cases -8 business lines ("b") $\times 7$ event types ("e") ${ }^{3}$. This matrix provides loss amounts corresponding to specific events (fraud, clients' practice, etc.) which are associated with banks' business units, and these losses are not considered as time series. For the whole set of cells, the bank needs to provide a risk measure, and then the capital required to face these risks. In the following, we compute these risks by business units (lines), by event types (columns) and for the global matrix. The specific loss data set we use for applications has been provided by the French Caisse d'Epargne. We use 99280 data points corresponding to events which occurred between 2006 and 2008. The descriptive statistics of the data sets are given in Appendix A.

Coming back to the core of our paper, we specify how we are going to work to associate a risk measure to the whole set of cells provided in Table 1. One of our objectives is to show that it is possible to use multivariate copulas to measure operational risks capital requirements, beyond the set of elliptical copulas (Gaussian and Student ones). The second objective is to show the influence of the margin and copulas choice on capital computations. We will see that the choices create large differences in the computation of the capital and, thus the regulator must be informed releasing the rules. We summarize our approach considering the following three steps:

- In a first step, we estimate the parameters of the severity distributions for the 10 cells of Table 1 (for which we have enough data sets) chosen among empirical, lognormal and Gumbel distributions ${ }^{4}$.

- In a second step, we estimate the dependence structures between these severities using nested copulas and vine architectures (Brechmann et al. (2010)). We use a pseudo maxi-

\footnotetext{
${ }^{3}$ The business lines are corporate finance, trading \& sales, retail banking, commercial banking, payment and settlement, agency services, asset management and retail brokerage. The event types are internal fraud, external fraud, employment practices \& workplace safety, clients, products \& business practices, damage to physical assets, business disruption \& system failures and execution, delivery \& process management.

${ }^{4}$ Other distributions have been tested but we only provide some results obtained using the Generalized Pareto Distribution in the fifth section
} 
mum likelihood method to estimate the copulas parameters (Mendes et al. (2007), Weiss (2010)) providing the value of the corresponding AIC (Akaike (1974)) in order to discriminate between different classes of copulas. We select our model following a triple statement: first, we only consider structures which fulfill the theoretical conditions of application; second between these structures we select the one that presents the lowest AIC; third, we select the structure which provides a conservative capital allocation (BCBS (2010)). We focus on Gumbel, Clayton and Frank copulas (Nelsen (2006)). We also use the Galambos copula (Galambos (1975)), the Husler-Reiss one (Hüsler and Reiss (1989)) and the Tawn (Silverman (1986)) one which are interesting because they enable non-linear and tail dependences to be taken into account. The multivariate Gaussian copula is also considered as a benchmark even if regarding the AIC it is always rejected.

- In a third step, after building the LDF which is a convolution of the distribution of the previous severities with a Poisson distribution (Guégan and Hassani (2009)), whose estimated parameters are provided in Appendix B, we apply the previous dependence structures on the severities to the $\mathrm{LDFs}^{5}$, and we derive the $99.9 \%$ quantile for this $n$-dimensional LDF which gives the final capital requirement.

\subsection{Estimations}

Using the data set introduced in Section two on the period 2006-2008 and denoting $F_{i}, i=$ $1, \ldots, 10$, the distributions of the severities corresponding to each cell of Table 1 , we proceed as follows to estimate the distributions $F_{i}$ and the dependence structure between the cells.

Using the empirical cdfs $F_{i}, i=1, \ldots, 10$ as marginal distribution, (Silverman (1986) and Wand and Jones (1995)), we focus on specific dependence structures between these severity distributions considering different decomposition of the Basel matrix. We first estimate the dependence between three subsets of cells which are important for the management of the bank because they correspond to specific sectors of activities, and finally we use them to study the whole matrix. We specify these sets:

\footnotetext{
${ }^{5}$ It should be recalled that we assume that the frequency data sets do not change the structure of dependence obtained from the severities.
} 


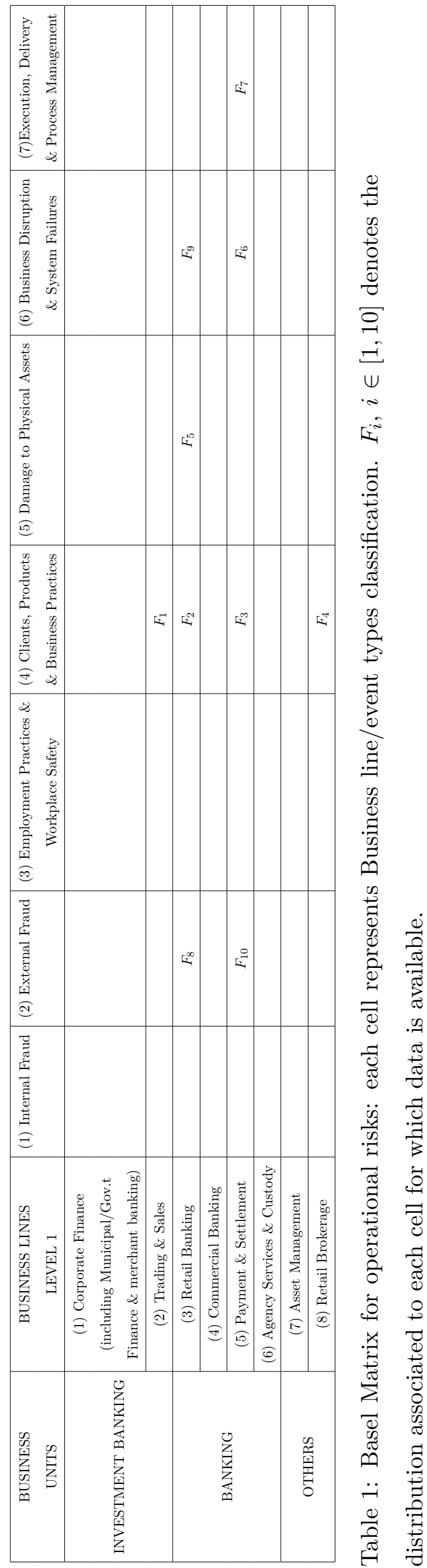


1. $F_{2}, F_{5}, F_{8}$ and $F_{9}$ which enable modelling event type dependences, considering the "Retail Banking" business unit;

2. $F_{3}, F_{6}, F_{7}$ and $F_{10}$ which enable modelling event type dependences, considering the "Payment and Settlement" business unit;

3. $F_{1}, F_{2}, F_{3}$ and $F_{4}$ which enable modelling business unit dependences, considering the "Client, Products \& Business Practices" event type; and

4. $F_{1}, F_{2}, F_{3}, F_{4}, F_{5}, F_{6}, F_{7}, F_{8}, F_{9}$ and $F_{10}$, which enable modelling dependencies of the whole Basel Matrix.

To compare the different methodologies presented previously, we successively link the three first sets using a multivariate Gaussian copula (denoted A), a partially nested copula (PNC), a fully nested copula (FNC), and finally a vine structure (D), considering Gumbel, Clayton, Frank, Galambos, Husler-Reiss and Tawn copulas in every case. In order to estimate the successive bivariate copulas parameters, we carry out pseudo-maximum likelihood methods following Mendes et al. (2007) and Weiss (2010). In table 3 we provide the estimated parameters for these three sets of 4 cells with the corresponding AIC. We observe that the PNC and FNC methodologies do not always give results for the dependence structures between the severities because the constraints on the copula parameters are not verified. For the Gaussian structure, we provide only the estimated correlation parameter $\rho$. For the vine approach, we provide the results only for the Gumbel copula because, examining the AIC, it is the best adjustment we obtain for all data sets among the previously mentioned copulas. Comparing adjustments between the multivariate Gaussian copula and the Gumbel one, with respect to the AIC, the last one provides the best adjustment. We also observe that the vine approach beats the nested one when we are able to adjust it on a data set: for instance for the subset $\left(F_{3}, F_{6}, F_{7}, F_{10}\right)$ (Table 3 , second column) whatever the copula we use.

Then we provide in Tables 4-6 the parameters obtained using a vine strategy modelling the dependence between the 10 severities (whole matrix), using a Gumbel copula (Table 4), a Clayton copula (Table 5) and, a mixture of numerous copula family architectures (Table 6). According to the AIC, the third architecture (A Frank copula on the top) copula appears as being the best 
adjustment.

To measure the dependence structure for the whole Basel Matrix (Table 1) reduced to four distributions (Table 2) we propose an alternative way. We consider a specific copula architecture using a Student copula to link these four LDF respectively denoted $B_{1}=F_{1}, B_{2}=C_{\theta_{2}}\left(F_{2}, F_{5}, F_{8}, F_{9}\right)$, $B_{3}=C_{\theta_{3}}\left(F_{3}, F_{6}, F_{7}, F_{10}\right)$, and $B_{4}=F_{4}$. The estimated parameters of the Student copula are given in Table 7. This structure will be denoted by the term "Overhead" in the following.

Comparing the vine approach and the mixture between the vines and the Student copula, we notice that the log-likelihood retains the vine (Table 6), but according to the AIC (due to the number of estimated parameters) we should retain the "Overhead" architecture. Nevertheless we continue our exercise with the two methodologies (vine and "Overhead" copula) and we compare the corresponding capital allocations in the next paragraph.

The choice of the vine decomposition mainly depends on a preliminary analysis of the Basel cells (Table 1). Indeed, the initial structure is given studying the risk supported by Business Units. In our case, we respectively have on the edge, the Retail Banking, the Trading and Sales, the Retail Brokerage and the Payment and Settlement.

\begin{tabular}{|c|c|c|}
\hline $\begin{array}{c}\text { BUSINESS } \\
\text { UNITS }\end{array}$ & $\begin{array}{c}\text { BUSINESS LINES } \\
\text { LEVEL 1 }\end{array}$ & Loss Distributions \\
\hline INVESTMENT BANKING & (2) Trading \& Sales & $B_{1}$ \\
\hline \multirow{2}{*}{ BANKING } & (3) Retail Banking & $B_{2}$ \\
\cline { 2 - 3 } & (5) Payment \& Settlement & $B_{3}$ \\
\hline OTHERS & (8) Retail Brokerage & $B_{4}$ \\
\hline
\end{tabular}

Table 2: Restricted Basel Matrix used to compute operational risk global capital allocation. $B_{1}$, $B_{2}, B_{3}, B_{4}$ are the four loss distributions used in the vine methodology. 


\subsection{Capital Requirements}

As soon as the dependence structure between the different cells of the Basel matrix is known, we use it to provide the corresponding capital requirement. An essential tool to obtain it is the Loss Distribution Function which is computed as a convolution of the distribution characterizing the severities with a Poisson distribution. We recall that the LDF is a mixture of distributions and details on the methods can be found in Chernobai et al. (2007), Guégan and Hassani (2009) and Guégan et al. (2011) among others.

To obtain the capital requirement associated with the LDF, first based on sets of 4 cells, then on the whole ten cells four strategies are considered and results are given in Tables 8 - 10 .

1. The first strategy consists in associating a VaR measure (and then the corresponding capital) to each cell, and sum the VaR for the corresponding number of cells. At each time we compute this VaR for the three severity distributions we previously retained (empirical, lognormal and Gumbel). The results of this strategy is provided on the first line of Table 9 for 4-dimensional data sets, and the first line of Table 10 for the whole matrix. We call this approach "univariate" in the Table.

2. To take into account the dependence structures estimated previously on the severities, in the second strategy, we link all the LDFs using a Gumbel copula because it is always the best one (the lowest AIC). Considering again the three distributions for the severities, we provide in Table 9 (middle line) the corresponding capital requirements for the 4dimensional data sets, and in Table 10 (bottom line) for the whole matrix using a Student copula.

3. In Table 8, we provide capital values using vines methodology for the 10 marginal distributions (following the strategies presented in Tables 4, 5 and 6 ).

4. In the last line of the Table 9, we provide the capital requirement using a multivariate Gaussian copula, although this adjustment is rejected during the estimation process.

From these results (Tables 8-10) some comments arise:

- We observe that the most conservative value for the capital requirement is obtained when the LDFs are computed as convolution of nonparametric distributions and Poisson distri- 
bution, whatever the strategy used. On the other hand, whatever the dependence structure and the set of severities we consider the largest risk exposure is obtained when we model the LDF as a convolution of Gumbel and Poisson distributions.

- Whatever the set of severities we consider, the multivariate Gaussian copula applied to the LDF computed as a convolution of lognormal and Poisson distributions provides the most conservative results. Note that this strategy is often used by practitioners, but in our case, the Gaussian copula is rejected according to the $\mathrm{AIC}^{6}$.

- The first line of Table 9 exhibits the less conservative results. It corresponds to the classical strategy used by practitioners (sum of the VaRs). Thus our proposal enables "moderating" the risk-taker behavior of financial agents, taking into account the dependence structure and providing more conservative values.

Now, in order to compute the global capital value based on the whole Basel Matrix, several strategies may be carried out using the lines and the columns of Table 1:

1. We can compute the VaR for each Basel category and sum the 10 corresponding VaRs. it is the strategy privileged by practitioners based on a common practice without analysis of the real data sets. ${ }^{7}$

2. Alternatively, we can use the vine methodology developed previously applying it to the whole structure following the scheme presented in the previous figures, using for instance an Archimedean copula whose parameter is given in Tables 4,5 and 6. This is the approach we have privileged in this paper because it lies on a robust computation of the dependence structure between the cells.

The final capital requirements computed using these two strategies with three different models for the LDFs (empirical (1), lognormal (2) and Gumbel (3)) are given in Table 10. We analyse the results provided in this one.

\footnotetext{
${ }^{6}$ We noticed that this conservative result is only due to the fact that we used CDFs to estimate the Gaussian copulas parameters.

${ }^{7}$ We can use the dependence structure previously obtained between the lines and sum the corresponding aggregated VaRs. We can use the same strategy working with the columns. We link vines copulas (for instance, the Gumbel ones) with a Student copula (Table 7).
} 
- The most conservative result is obtained using the Gumbel dependence structure when the LDF is estimated using a convolution of Poisson and non-parametric distributions: $€ 76$ 966585 (If we do not consider the sum of univariate VaRs as a viable solution)).

- The less conservative result is obtained when we use the "Overhead" structure when each LDF is computed as a convolution of Poisson and lognormal distribution: $€ 25277957$.

We observe that our approach taking into account a dependence structure which captures extreme events and their frequency provides the most conservative result. It is important to note that the methodology behind this result is very easy to carry out and could be used by practitioners. We now analyze some points which can be interesting for application purposes.

\section{Further developments}

In this section, we focus on several important points we have encountered during the previous process applying the vine approach in order to compute the capital requirement associated to Table 1.

1. Table 9 provides the capital amount for a global set of 4 severities. We can derive by projection the amount corresponding to each severity. This capital is given in Tables 11

- 13. For example, for the fourth column corresponding to "Clients, Products \& Business Practices", we can provide the amounts pertaining independently to the "Retail Banking", the "Trading \& Sales", the "Payment \& Settlement" and the "Retail Brokerage" business lines. Our approach is interesting because we provide the capital for each cell through the dependence structure between the cells. This approach is totally different of the approach used by practitioners who directly compute the capital associated to a cell without taking into account the information given by the other cells.

2. When we estimate dynamically the parameter of the dependence structure we observe important variations in the values of the Gumbel copula parameter. We illustrate this fact in Table 14. We have computed the parameter of the Gumbel copula linking the LDFs of the cells $F_{9}$ and $F_{6}$. This parameter $\theta$ varies with respect to the information set used for its estimation : the value obtained using the year 2006, is different when we use the year 2007 or the year 2008, or the whole sample. We notice that the upper tail dependence is larger 
when we use this last data set. This will have an impact for the computation of capital requirements. Thus, with respect to the information set we use, the capital requirement appears to be more or less conservative.

3. The impact of the choice of the severity distributions associated with the choice of the dependence structure between these severities is crucial for the computation of the capital requirement. We illustrate this fact using the distribution which characterizes the cell $F_{9}$ corresponding to Business Disruption \& System Failure events in the Retail Banking business unit and the distribution associated to the cell $F_{6}$ characterizing the same events in the Payment \& Settlement business unit. For the distribution $F_{9}$ we use a Gumbel distribution or a lognormal distribution, for the distribution $F_{6}$ we use a Generalized Pareto distribution (GPD) or a lognormal distribution. Table 15 provides the capital values when we link these two distributions with a Gumbel copula on one hand and with a Clayton copula on another hand. We give the projections of the capital for each cell and also the global value. Table 15 shows that depending on the way we model the marginal distributions, we have tremendous differences between the VaRs. For example, we would have a VaR equal to 117207402 euros if $F_{9}$ is modeled with a lognormal distribution and $F_{6}$ with a GPD distribution versus a VaR equal to 2037655 euros if $F_{9}$ is modeled with a lognormal distribution and $F_{6}$ with a Gumbel one. Depending on the way we model the LDFs, the aggregated VaR may be multiplied by 57.52. The same behavior is observable when we project the corresponding values on the cells. For example, the multivariate VaR projection on $F_{9}$ is $€ 2655055$ if $F_{6}$ is modeled using a lognormal distribution, and is equal to $€ 15405192$ if $F_{6}$ is modeled using a GPD distribution. The peak for the VaR observed in that latter case is due to the caption of extreme events through the choice of the marginal distributions.

4. In Table 15 we observe also that the capital requirements obtained using a Gumbel copula are always bigger than the one obtained with a Clayton one, thus the choice of the dependence structure has also an important impact on the computation of the capital. Finally, using at the same time, copula and severity distributions which take into account information in the tail provides very accurate results. Indeed, when we model $F_{6}$ using a GPD associated with a Gumbel copula, we provide a larger VaR than with the Clayton 
one. We have to compare the amounts $€ 105422356$ with $€ 103249260$ on the one hand, and $€ 117207402$ with $€ 107807238$ on the other.

In conclusion, all these results point the importance of the marginal distributions' and copula's modellings to associate a "correct" capital allocation with any risk.

\section{Conclusion}

This paper proposes a new methodology to compute the capital requirement associated with a large number of operational risks categories (i.e. n-dimension copulas). We focus on the vine copula architecture which permits the choice of the marginal distributions and of the copulas. We can retain the following main improvements for practitioners:

- Firstly, this methodology enables the use of numerous classes of copulas without being restricted to the elliptic domain. One can consider copulas which focus on information contained in the tails, where we find the large losses. Recently, we have also shown (Guegan and Hassani (2011)) that regarding our data sets and the Expected Shortfall as an accurate risk measure, the choice of the Copula structure has a tremendous impact on the capital requirement. We did not observe this impact when using the VaR.

- Secondly, our approach allows several combinations of marginal distributions to derive robust adjustments in the statistical sense.

- Thirdly, even working in the high dimension, the procedure is easy to implement and is not too time consuming ${ }^{8}$.

- Finally, our method complies with the new Basel Committee (BCBS (2010)) requirements.

Let us note that the complete Basel matrix could contain more than 250 cells. The open question is to be able to work with such a large matrix, whilst limiting the time of computation. Recent developments based on parallel computing could be an interesting solution in the future (Brechmann et al. (2010)).

\footnotetext{
${ }^{8}$ The provided results were obtained with a computer with common capacities i.e. Pentium $4,3 \mathrm{GHz}$ and $1 \mathrm{~GB}$ of RAM. We implemented the method with "R-2.11.0". We had no opportunity to parallelized the simulation procedure, therefore each run took between 15 to 30 minutes.
} 
The methodology presented in this paper can be applied to any computation for risk measurement and it is not limited to operational risks. The main philosophy of this paper is to provide a robust and easy tool to associate a measure for a large number of risks, bypassing for the dependence structure the elliptical approach which is not always adapted to the reality. 


\begin{tabular}{|c|c|c|c|c|c|c|}
\hline Structures & $C_{2589}\left(F_{2}, F_{5}, F_{8}, F_{9}\right)$ & $A I C$ & $C_{36710}\left(F_{3}, F_{6}, F_{7}, F_{10}\right)$ & $A I C$ & $C_{1234}\left(F_{1}, F_{2}, F_{3}, F_{4}\right)$ & $A I C$ \\
\hline $\begin{array}{c}(\mathrm{A}) \\
\text { Gaussian }\end{array}$ & $\begin{array}{c}\rho=0.665 \\
(0.0438)\end{array}$ & -14.398 & $\begin{array}{c}\rho=0.682 \\
(0.0422)\end{array}$ & -14.367 & $\begin{array}{c}\rho=0.681 \\
(0.032)\end{array}$ & -13.918 \\
\hline $\begin{array}{c}(\mathrm{B}) \\
P N C\end{array}$ & $\oslash$ & - & $\oslash$ & - & $\begin{array}{c}\theta=1.919 \\
(0.498)\end{array}$ & -14.211 \\
\hline $\begin{array}{l}(\mathrm{C}) \\
F N C\end{array}$ & $\oslash$ & - & $\oslash$ & - & $\oslash$ & - \\
\hline $\begin{array}{c}\text { (D) } \\
\text { PairCopula }\end{array}$ & $\begin{array}{c}\theta=17.353 \\
(0.642)\end{array}$ & -14.592 & $\begin{array}{c}\theta=3.764 \\
(0.579)\end{array}$ & -14.415 & $\begin{array}{c}\theta=5.345 \\
(0.889)\end{array}$ & -14.355 \\
\hline
\end{tabular}

Table 3: Parameters estimation for several dependence structures applied to three sets of four severities. The corresponding standard deviations are provided in brackets. "Gaussian" denotes a multivariate Gaussian copula structure, "FNC" denotes Fully Nested copulas, "PNC" denotes Partially Nested copulas and "Pair Copula" denotes a Vine structure. A workable nested structure has been found when the dependence degree was decreasing and the level of nesting increasing. For the copulas $C_{2589}$ and $C_{36710}$ the AIC is better for the Pair Copula structure than for the Gaussian one. Considering the dependence between $F_{1}, F_{2}, F_{3}$ and $F_{4}$, the AIC is better for the Pair Copula structure than for the Nested one. In all cases, the robust dependence structure is provided by a Gumbel copula. 


\begin{tabular}{|c|c|c|c|c|c|c|c|c|c|}
\hline Level & \multicolumn{9}{|c|}{ Parameter Estimates } \\
\hline 9 & $\begin{array}{c}3.17 \\
(0.31)\end{array}$ & & & & & & & & \\
\hline 8 & $\begin{array}{c}3.02 \\
(0.17)\end{array}$ & $\begin{array}{c}3.41 \\
(0.25)\end{array}$ & & & & & & & \\
\hline 7 & $\begin{array}{c}3.06 \\
(0.17)\end{array}$ & $\begin{array}{c}2.99 \\
(0.24)\end{array}$ & $\begin{array}{c}3.52 \\
(0.33)\end{array}$ & & & & & & \\
\hline 6 & $\begin{array}{c}3.34 \\
(0.25)\end{array}$ & $\begin{array}{c}3.47 \\
(0.24)\end{array}$ & $\begin{array}{c}3.66 \\
(0.31)\end{array}$ & $\begin{array}{c}3.29 \\
(0.24)\end{array}$ & & & & & \\
\hline 5 & $\begin{array}{c}3.58 \\
(0.34)\end{array}$ & $\begin{array}{c}3.43 \\
(0.34)\end{array}$ & $\begin{array}{c}3.24 \\
(0.27)\end{array}$ & $\begin{array}{c}3.41 \\
(0.35)\end{array}$ & $\begin{array}{c}3.52 \\
(0.26)\end{array}$ & & & & \\
\hline 4 & $\begin{array}{c}2.96 \\
(0.22)\end{array}$ & $\begin{array}{c}3.21 \\
(0.22)\end{array}$ & $\begin{array}{c}3.45 \\
(0.29)\end{array}$ & $\begin{array}{c}3.49 \\
(0.25)\end{array}$ & $\begin{array}{c}3.60 \\
(0.29)\end{array}$ & $\begin{array}{c}3.28 \\
(0.25)\end{array}$ & & & \\
\hline 3 & $\begin{array}{c}3.42 \\
(0.22)\end{array}$ & $\begin{array}{c}3.30 \\
(0.21)\end{array}$ & $\begin{array}{c}3.04 \\
(0.22)\end{array}$ & $\begin{array}{c}3.29 \\
(0.31)\end{array}$ & $\begin{array}{c}3.10 \\
(0.20)\end{array}$ & $\begin{array}{c}3.00 \\
(0.25)\end{array}$ & $\begin{array}{c}3.16 \\
(0.25)\end{array}$ & & \\
\hline 2 & $\begin{array}{c}3.03 \\
(0.24)\end{array}$ & $\begin{array}{c}3.00 \\
(0.20)\end{array}$ & $\begin{array}{c}3.07 \\
(0.26)\end{array}$ & $\begin{array}{c}2.53 \\
(0.64)\end{array}$ & $\begin{array}{c}2.78 \\
(0.60)\end{array}$ & $\begin{array}{c}2.95 \\
(0.36)\end{array}$ & $\begin{array}{c}3.27 \\
(0.52)\end{array}$ & $\begin{array}{c}3.14 \\
(0.23)\end{array}$ & \\
\hline 1 & $\begin{array}{c}1.60 \\
(0.11)\end{array}$ & $\begin{array}{c}3.02 \\
(0.16)\end{array}$ & $\begin{array}{c}1.83 \\
(0.13)\end{array}$ & $\begin{array}{c}2.89 \\
(0.28)\end{array}$ & $\begin{array}{c}3.88 \\
(0.45)\end{array}$ & $\begin{array}{c}1.46 \\
(0.09)\end{array}$ & $\begin{array}{c}1.59 \\
(0.10)\end{array}$ & $\begin{array}{c}2.42 \\
(0.17)\end{array}$ & $\begin{array}{c}1.63 \\
(0.13)\end{array}$ \\
\hline
\end{tabular}

Table 4: This table presents estimates at each node of a Vine built with Gumbel copulas regarding the ten marginal distributions: $F_{1}, \ldots, F_{10}$. The standard deviations are provided in brackets. The AIC equals 79.19778. 


\begin{tabular}{|c|c|c|c|c|c|c|c|c|c|}
\hline Level & \multicolumn{9}{|c|}{ Parameter Estimates } \\
\hline 9 & $\begin{array}{c}1.44 \\
(0.14)\end{array}$ & & & & & & & & \\
\hline 8 & $\begin{array}{c}1.32 \\
(0.15)\end{array}$ & $\begin{array}{c}1.24 \\
(0.18)\end{array}$ & & & & & & & \\
\hline 7 & $\begin{array}{c}1.14 \\
(0.17)\end{array}$ & $\begin{array}{c}1.14 \\
(0.17)\end{array}$ & $\begin{array}{c}1.25 \\
(0.18)\end{array}$ & & & & & & \\
\hline 6 & $\begin{array}{c}1.38 \\
(0.26)\end{array}$ & $\begin{array}{c}1.06 \\
(0.17)\end{array}$ & $\begin{array}{c}1.05 \\
(0.19)\end{array}$ & $\begin{array}{c}1.11 \\
(0.17)\end{array}$ & & & & & \\
\hline 5 & $\begin{array}{c}1.10 \\
(0.15)\end{array}$ & $\begin{array}{c}1.16 \\
(0.15)\end{array}$ & $\begin{array}{c}1.02 \\
(0.15)\end{array}$ & $\begin{array}{c}1.12 \\
(0.17)\end{array}$ & $\begin{array}{c}1.29 \\
(0.16)\end{array}$ & & & & \\
\hline 4 & $\begin{array}{c}1.32 \\
(0.14)\end{array}$ & $\begin{array}{c}1.23 \\
(0.11)\end{array}$ & $\begin{array}{c}1.32 \\
(0.16)\end{array}$ & $\begin{array}{c}0.99 \\
(0.12)\end{array}$ & $\begin{array}{c}1.33 \\
(0.14)\end{array}$ & $\begin{array}{c}1.15 \\
(0.17)\end{array}$ & & & \\
\hline 3 & $\begin{array}{c}1.20 \\
(0.20)\end{array}$ & $\begin{array}{c}1.31 \\
(0.18)\end{array}$ & $\begin{array}{c}1.02 \\
(0.14)\end{array}$ & $\begin{array}{c}1.28 \\
(0.25)\end{array}$ & $\begin{array}{c}1.05 \\
(0.21)\end{array}$ & $\begin{array}{c}1.15 \\
(0.18)\end{array}$ & $\begin{array}{c}1.38 \\
(0.25)\end{array}$ & & \\
\hline 2 & $\begin{array}{c}0.95 \\
(0.23)\end{array}$ & $\begin{array}{c}1.02 \\
(0.15)\end{array}$ & $\begin{array}{c}1.30 \\
(0.17)\end{array}$ & $\begin{array}{c}1.17 \\
(0.21)\end{array}$ & $\begin{array}{c}1.15 \\
(0.15)\end{array}$ & $\begin{array}{c}1.02 \\
(0.13)\end{array}$ & $\begin{array}{c}1.44 \\
(0.21)\end{array}$ & $\begin{array}{c}1.22 \\
(0.16)\end{array}$ & \\
\hline 1 & $\begin{array}{c}0.36 \\
(0.11)\end{array}$ & $\begin{array}{c}2.89 \\
(0.21)\end{array}$ & $\begin{array}{c}0.80 \\
(0.12)\end{array}$ & $\begin{array}{c}1.27 \\
(0.22)\end{array}$ & $\begin{array}{c}1.78 \\
(0.40)\end{array}$ & $\begin{array}{c}0.26 \\
(0.10)\end{array}$ & $\begin{array}{c}0.47 \\
(0.12)\end{array}$ & $\begin{array}{c}1.14 \\
(0.15)\end{array}$ & $\begin{array}{c}0.42 \\
(0.12)\end{array}$ \\
\hline
\end{tabular}

Table 5: This table presents estimates at each node of a Vine built with Clayton copulas regarding the ten marginal distributions: $F_{1}, \ldots, F_{10}$. The standard deviations are provided in brackets. The AIC equals 79.73638 . 


\begin{tabular}{|c|c|c|c|c|c|c|c|c|c|}
\hline Level & \multicolumn{9}{|c|}{ Parameter Estimates } \\
\hline 9 & $\begin{array}{l}\text { Frank } \\
12.95 \\
(1.24)\end{array}$ & & & & & & & & \\
\hline 8 & $\begin{array}{l}\text { Frank } \\
13.43 \\
(1.32)\end{array}$ & $\begin{array}{c}\text { Galambos } \\
2.38 \\
(0.24)\end{array}$ & & & & & & & \\
\hline 7 & $\begin{array}{c}\text { Husler-Reiss } \\
3.62 \\
(0.32)\end{array}$ & $\begin{array}{c}\text { Gumbel } \\
3.75 \\
(0.30)\end{array}$ & $\begin{array}{l}\text { Frank } \\
13.49 \\
(1.32)\end{array}$ & & & & & & \\
\hline 6 & $\begin{array}{c}\text { Galambos } \\
\qquad \begin{array}{c}2.99 \\
(0.38)\end{array}\end{array}$ & $\begin{array}{l}\text { Frank } \\
13.84 \\
(1.29)\end{array}$ & $\begin{array}{c}\text { Gumbel } \\
3.45 \\
(0.33)\end{array}$ & $\begin{array}{l}\text { Frank } \\
12.83 \\
(1.38)\end{array}$ & & & & & \\
\hline 5 & $\begin{array}{c}\text { Husler-Reiss } \\
3.07 \\
(0.27)\end{array}$ & $\begin{array}{c}\text { Galambos } \\
2.70 \\
(0.33)\end{array}$ & $\begin{array}{l}\text { Frank } \\
13.35 \\
(1.21)\end{array}$ & $\begin{array}{c}\text { Gumbel } \\
3.46 \\
(0.32)\end{array}$ & $\begin{array}{l}\text { Frank } \\
12.94 \\
(1.15)\end{array}$ & & & & \\
\hline 4 & $\begin{array}{l}\text { Frank } \\
13.47 \\
(1.13)\end{array}$ & $\begin{array}{c}\text { Gumbel } \\
3.25 \\
(0.20)\end{array}$ & $\begin{array}{c}\text { Galambos } \\
\qquad \begin{array}{c}2.58 \\
(0.22)\end{array}\end{array}$ & $\begin{array}{c}\text { Gumbel } \\
3.33 \\
(0.23)\end{array}$ & $\begin{array}{l}\text { Frank } \\
14.06 \\
(1.43)\end{array}$ & $\begin{array}{c}\text { Clayton } \\
1.19 \\
(0.23)\end{array}$ & & & \\
\hline 3 & $\begin{array}{c}\text { Gumbel } \\
3.44 \\
(0.26)\end{array}$ & $\begin{array}{c}\text { Galambos } \\
2.96 \\
(0.29)\end{array}$ & $\begin{array}{c}\text { Husler-Reiss } \\
\qquad \begin{array}{c}3.06 \\
(0.26)\end{array}\end{array}$ & $\begin{array}{c}\text { Galambos } \\
2.89 \\
(0.32)\end{array}$ & $\begin{array}{c}\text { Gumbel } \\
3.40 \\
(0.29)\end{array}$ & $\begin{array}{l}\text { Frank } \\
13.81 \\
(1.24)\end{array}$ & $\begin{array}{c}\text { Clayton } \\
1.12 \\
(0.19)\end{array}$ & & \\
\hline 2 & $\begin{array}{c}\text { Galambos } \\
\qquad \begin{array}{c}2.16 \\
(0.32)\end{array}\end{array}$ & $\begin{array}{l}\text { Frank } \\
13.96 \\
(1.51)\end{array}$ & $\begin{array}{c}\text { Galambos } \\
\qquad \begin{array}{c}2.83 \\
(0.24)\end{array}\end{array}$ & $\begin{array}{c}\text { Gumbel } \\
3.55 \\
(0.32)\end{array}$ & $\begin{array}{c}\text { Gumbel } \\
3.65 \\
(0.36)\end{array}$ & $\begin{array}{l}\text { Frank } \\
13.67 \\
(1.33)\end{array}$ & $\begin{array}{c}\text { Husler-Reiss } \\
3.49 \\
(0.26)\end{array}$ & $\begin{array}{c}\text { Clayton } \\
0.72 \\
(0.30)\end{array}$ & \\
\hline 1 & $\begin{array}{c}\text { Franck } \\
3.24 \\
(0.49)\end{array}$ & $\begin{array}{c}\text { Gumbel } \\
3.02 \\
(0.16)\end{array}$ & $\begin{array}{c}\text { Clayton } \\
0.80 \\
(0.12)\end{array}$ & $\begin{array}{c}\text { Galambos } \\
2.19 \\
(0.28)\end{array}$ & $\begin{array}{c}\text { Husler-Reiss } \\
\qquad \begin{array}{c}3.61 \\
(0.41)\end{array}\end{array}$ & $\begin{array}{l}\text { Tawn } \\
3.85 \\
(0.09)\end{array}$ & $\begin{array}{c}\text { Gumbel } \\
1.59 \\
(0.10)\end{array}$ & $\begin{array}{c}\text { Clayton } \\
1.14 \\
(0.15)\end{array}$ & $\begin{array}{c}\text { Frank } \\
3.58 \\
(0.53)\end{array}$ \\
\hline
\end{tabular}

Table 6: This table presents estimates at each node of a Vine built with 6 different copulas regarding the ten marginal distributions: $F_{1}, \ldots, F_{10}$. The standard deviations are provided in brackets. The AIC equals 78.95918 . 


\begin{tabular}{|c|c|c|}
\hline Structures & $C_{B_{1}, B_{2}, B_{3}, B_{4}}$ & $\mathrm{AIC}$ \\
\hline Student Copula & $\rho=(0.02857775,0.83355628,0.08367086$, & 46.83165 \\
& $, 0.01551715,-0.17840772,0.03647245)$ & \\
& $(0.002,0.1,0.07,0.001,0.05,0.001)$ & \\
\hline
\end{tabular}

Table 7: This table provides the Student copula parameters obtained modeling the dependence structure between all business lines. The corresponding standard deviations are provided in brackets. 


\begin{tabular}{|c|c|c|}
\hline Approach & LDF & $C_{\text {Global }}\left(F_{1}, \ldots, F_{10}\right)$ \\
\hline \multirow{3}{*}{ Univariate } & 1 & 77018239 \\
& 2 & 74360305 \\
& 3 & 48871039 \\
\hline \multirow{3}{*}{ Gumbel Copula } & 1 & 76966585 \\
& 2 & 73495616 \\
& 3 & 48851507 \\
\hline \multirow{3}{*}{ Frank Copula } & 2 & 69647495 \\
& 3 & 48294940 \\
\hline \multirow{3}{*}{ Clayton Copula } & 2 & 64659214 \\
& 3 & 47887230189 \\
\hline
\end{tabular}

Table 8: This table provides the capital allocation for the whole data set, considering three classes of severities (1 denotes the non parametric approach of the LDF, 2 the lognormal approach and 3 the Gumbel one.) and three classes of dependence, a Gumbel structure, a Frank one and a Clayton architecture. The term Univariate corresponds to the VaRs sum of each LDF. 


\begin{tabular}{|c|c|c|c|c|}
\hline Approach & $\mathrm{LDF}$ & $C_{1234}\left(L D F_{1}, L D F_{2}, L D F_{3}, L D F_{4}\right)$ & $C_{2589}\left(L D F_{2}, L D F_{5}, L D F_{8}, L D F_{9}\right)$ & $C_{36710}\left(L D F_{3}, L D F_{6}, L D F_{7}, L D F_{10}\right)$ \\
\hline \multirow{5}{*}{ Univariate } & 1 & 29400454 & 39287139 & 28449066 \\
& 2 & 22794418 & 24118977 & 34614408 \\
& 3 & 8968115 & 25755128 & 15719280 \\
\hline \multirow{5}{*}{ Gumbel } & 1 & 30646550 & 41456461 & 33252197 \\
& 2 & 35474559 & 56176428 & 60970007 \\
& 3 & 21778827 & 25798375 & 15762291 \\
\hline \multirow{3}{*}{ Gaussian } & 2 & 31257604 & 43621089 & 37158832 \\
& 3 & 40651444 & 75785269 & 68385483 \\
& 21381957 & 25972225 & 15881606 \\
\hline
\end{tabular}

Table 9: This table provides the capital allocation (a 99.9\% VaR) for 4-dimensional data sets, considering three classes of severities ( 1 denotes the non parametric approach of the LDF, 2 the lognormal approach and 3 the Gumbel one.) and three classes of dependence. Univariate corresponds to the VaRs sum of each LDF, Gumbel corresponds to the Gumbel copula and Gaussian to the multivariate Gaussian copula. 


\begin{tabular}{|c|c|c|}
\hline Approach & LDF & $C_{\text {Global }}\left(B_{1}, B_{2}, B_{3}, B_{4}\right)$ \\
\hline \multirow{3}{*}{ Univariate } & 1 & 77018239 \\
& 2 & 74360305 \\
& 3 & 48871039 \\
\hline \multirow{3}{*}{ Student Copula } & 1 & 41853691 \\
& 2 & 25277957 \\
& 3 & 33980264 \\
\hline
\end{tabular}

Table 10: This table provides the capital allocation for the whole data set, considering three classes of severities (1 denotes the non parametric approach of the LDF, 2 the lognormal approach and 3 the Gumbel one.) and two classes of dependence. Univariate corresponds to the VaRs sum of each LDF, Student corresponds to the Student copula used considering that $B_{2}$ and $B_{3}$ are themselves vine structure and $B_{1}$ and $B_{4}$ univariate LDFs (Table 2).

\begin{tabular}{|c|c|c|c|c|c|}
\hline Approach & LDF & $L D F_{1}$ & $L D F_{2}$ & $L D F_{3}$ & $L D F_{4}$ \\
\hline \multirow{3}{*}{ Univariate } & 1 & 278423 & 19650986 & 467434 & 9003611 \\
& 2 & 254095 & 6240984 & 926513 & 15372825 \\
& 3 & 232591 & 13590317 & 212451 & 7164041 \\
\hline \multirow{3}{*}{ Gumbel Copula } & 1 & 280423 & 20556466 & 524137 & 9285523 \\
& 3 & 377479 & 9957836 & 6283207 & 18856037 \\
\hline \multirow{3}{*}{ Gaussian Copula } & 2 & 609358 & 9862421 & 3098797 & 27080869 \\
& 3 & 237529 & 13632720 & 213645 & 7298063 \\
\hline
\end{tabular}

Table 11: This table provides the VaRs associated with each LDF of the set $L D F_{1}, L D F_{2}$, $L D F_{3}$ and $L D F_{4}$ when we decompose the dependence structure of the 4-dimensional set $C_{1234}$, considering three classes of severities ( 1 denotes the non parametric approach of the LDF, 2 the lognormal approach and 3 the Gumbel one.). 


\begin{tabular}{|c|c|c|c|c|c|}
\hline Approach & $\mathrm{LDF}$ & $L D F_{2}$ & $L D F_{5}$ & $L D F_{8}$ & $L D F_{9}$ \\
\hline \multirow{3}{*}{ Univariate } & 1 & 19650986 & 3182731 & 14212411 & 2241011 \\
\hline & 2 & 6240984 & 2151627 & 11676534 & 4049831 \\
\hline & 3 & 13599313 & 2478087 & 8599313 & 1087410 \\
\hline \multirow{3}{*}{ Gumbel Copula } & 1 & 20578056 & 3300471 & 15191828 & 2386106 \\
\hline & 2 & 10732933 & 2310337 & 29525155 & 13608000 \\
\hline & 3 & 13617419 & 2486453 & 8603916 & 10905587 \\
\hline \multirow{3}{*}{ Gaussian Copula } & 1 & 22269192 & 3301720 & 15482009 & 2568168 \\
\hline & 2 & 14264778 & 4157787 & 30072894 & 27259810 \\
\hline & 3 & 13692945 & 2492189 & 8679579 & 1107512 \\
\hline
\end{tabular}

Table 12: This table provides the VaRs associated with each LDF of the set $L D F_{2}, L D F_{5}$, $L D F_{8}$ and $L D F_{9}$ when we decompose the dependence structure of the 4-dimensional set $C_{2589}$, considering three classes of severities ( 1 denotes the non parametric approach of the LDF, 2 the lognormal approach and 3 the Gumbel one.). 


\begin{tabular}{|c|c|c|c|c|c|}
\hline Approach & LDF & $L D F_{3}$ & $L D F_{6}$ & $L D F_{7}$ & $L D F_{10}$ \\
\hline \multirow{3}{*}{ Univariate } & 1 & 467435 & 2739085 & 1295941 & 23946606 \\
& 2 & 926513 & 306553 & 2425710 & 30955632 \\
& 3 & 212451 & 772003 & 829360 & 13905464 \\
\hline \multirow{3}{*}{ Gumbel Copula } & 2 & 628263 & 3220812 & 1473900 & 27929223 \\
& 3 & 213844 & 775924 & 831552 & 13940970 \\
\hline \multirow{3}{*}{ Gaussian Copula } & 2 & 584053 & 3572152 & 1394149 & 31608479 \\
& 3 & 216849 & 789476 & 831840 & 14053440 \\
\hline
\end{tabular}

Table 13: This table provides the VaRs associated with each LDF of the set $L D F_{3}, L D F_{6}$, $L D F_{7}$ and $L D F_{10}$ when we decompose the dependence structure of the 4-dimensional set $C_{36710}$, considering three classes of severities ( 1 denotes the non parametric approach of the LDF, 2 the lognormal approach and 3 the Gumbel one.).

\begin{tabular}{|c|c|c|}
\hline Year & $\theta$ & $\theta$ \\
\hline 2006 & $4.9202(0.94)$ & \\
2007 & $3.7206(0.75)$ & $10.6610(0.88)$ \\
2008 & $5.8490(0.51)$ & \\
\hline
\end{tabular}

Table 14: Parameter estimation of Gumbel copulas estimated on $F_{9}$ and $F_{6}$ for each year 2006, 2007 and 2008 (second column). These parameters are compared to a Gumbel copula parameter estimated on the whole chronicle (third column). The corresponding standard deviation are provided in brackets. 


\begin{tabular}{|c|c|c|c|c|c|c|}
\hline Model & \multicolumn{3}{|c|}{ Gumbel Copula } & \multicolumn{3}{c|}{ Clayton Copula } \\
\hline & $L D F_{9}$ & $L D F_{6}$ & Sum & $L D F_{9}$ & $L D F_{6}$ & Sum \\
\hline Gumbel-GPD & 2322782 & 103099574 & 105422356 & 1154681 & 102094579 & 103249260 \\
Gumbel-lognormal & 1471343 & 566312 & 2037655 & 1455693 & 649164 & 2104857 \\
lognormal-GPD & 15405192 & 101802210 & 117207402 & 5631004 & 102176234 & 107807238 \\
\hline
\end{tabular}

Table 15: For the LDF corresponding to $F_{9}$ and $F_{6}$ we provide the VaRs computed from Gumbel and Clayton copulas for the year 2006. They are given respectively for three classes of severities. For instance, "Gumbel-GPD" means that we have chosen a Gumbel distribution to model $F_{9}$ and a mix of a lognormal and a GPD to model $F_{6}$.

\section{A Appendix: Distributions statistics}

Next table provides the four first moments of the empirical severities used in this paper.

\begin{tabular}{|c|c|c|c|c|}
\hline Distributions & Mean & Variance & Skewness & Kurtosis \\
\hline$F_{1}$ & 195.37 & 292732.86 & 7.31 & 71.69 \\
$F_{2}$ & 1522.83 & 372183311.54 & 27.57 & 910.13 \\
$F_{3}$ & 175.42 & 3804557.63 & 30.03 & 956.75 \\
$F_{4}$ & 1805.81 & 93274002.03 & 18.74 & 457.58 \\
$F_{5}$ & 1824.95 & 189175093.33 & 17.79 & 354.00 \\
$F_{6}$ & 1200.08 & 438224165.80 & 23.69 & 563.48 \\
$F_{7}$ & 800.14 & 24268504.39 & 10.88 & 139.39 \\
$F_{8}$ & 1779 & 1602373386 & 19.27 & 435.88 \\
$F_{9}$ & 1824.95 & 189175093.3 & 17.79 & 354.00 \\
$F_{10}$ & 12104 & 519962084.2 & 108.03 & 11806.23 \\
\hline
\end{tabular}

Table 16: Statistics of the data sets used. The distributions are right skewed and present large kurtosis. 


\section{B Appendix: LDF Parameters}

This appendix provides LDF's parameters estimations regarding considered models.

\begin{tabular}{|c|c|c|c|c|c|}
\hline Distributions & Poisson & \multicolumn{2}{|c|}{ lognormal } & \multicolumn{2}{|c|}{ Gumbel } \\
\hline$F_{1}$ & $\lambda=1094$ & $\mu=4.03$ & $\sigma=1.47$ & $u=149.88$ & $\beta=72.98$ \\
$F_{2}$ & $\lambda=8448$ & $\mu=4.25$ & $\sigma=1.97$ & $u=1381.07$ & $\beta=210.43$ \\
$F_{3}$ & $\lambda=1114$ & $\mu=2.80$ & $\sigma=2.23$ & $u=150.02$ & $\beta=40.65$ \\
$F_{4}$ & $\lambda=3811$ & $\mu=5.72$ & $\sigma=1.99$ & $u=1443.89$ & $\beta=585.89$ \\
$F_{5}$ & $\lambda=521$ & $\mu=4.87$ & $\sigma=2.19$ & $u=848.76$ & $\beta=471.77$ \\
$F_{6}$ & $\lambda=575$ & $\mu=4.03$ & $\sigma=1.71$ & $u=1101.79$ & $\beta=143.73$ \\
$F_{7}$ & $\lambda=937$ & $\mu=3.72$ & $\sigma=2.27$ & $u=721.71$ & $\beta=135.75$ \\
$F_{8}$ & $\lambda=1178$ & $\mu=5.42$ & $\sigma=2.14$ & $u=4010.25$ & $\beta=833.45$ \\
$F_{9}$ & $\lambda=8748$ & $\mu=4.87$ & $\sigma=2.19$ & $u=1612.31$ & $\beta=370.63$ \\
$F_{10}$ & $\lambda=12103$ & $\mu=5.49$ & $\sigma=2.00$ & $u=861.38$ & $\beta=437.14$ \\
\hline
\end{tabular}

Table 17: This table provides the parameters estimation for each LDF for the year 2008, assuming a Poisson distribution to model the frequencies, and either a lognormal or a Gumbel distribution to model the severities.

\begin{tabular}{|c|c|c|}
\hline Distributions & \multicolumn{2}{|r|}{ Poisson-Gumbel } \\
\hline$L D F_{9}$ & $\lambda=658$ & $\begin{array}{c}u=191.5378, \beta=938.9768 \\
(\text { s.e. } 36.70),(\text { s.e. } 35.64)\end{array}$ \\
\hline Distributions & \multicolumn{2}{|r|}{ Poisson-GPD } \\
\hline$L D F_{6}$ & $\lambda=1292$ & $\begin{array}{c}\mu=5.70, \sigma=1.10 \\
u=1645.07, \beta=932.854, \xi=0.767\end{array}$ \\
\hline
\end{tabular}

Table 18: This table provides two LDFs' parameters, $L D F_{6}$ and $L D F_{9}$, for the year 2006, assuming a Poisson distribution to model the frequencies and either a Gumbel or a mix of a lognormal and a GPD to model the severities. 


\section{Appendix: Value-at-Risk}

Recall that given a confidence level $\alpha \in[0,1]$, the VaR associated to a random variable $X$ is given by the smallest number $x$ such that the probability that $X$ exceeds $x$ is not larger than $(1-\alpha)$.

$$
\operatorname{VaR}_{(1-\alpha) \%}=\inf (x \in \mathbb{R}: P(X>x) \leq(1-\alpha))
$$




\section{References}

Aas, K., Czado, C., Frigessi, A. and Bakken, H. (2009), 'Pair copula constructions of multiple dependence.', Insur. Math. Econ. 44, 182-198.

Akaike, H. (1974), 'A new look at the statistical model identification.', IEEE Transactions on Automatic Control 19, 716-723.

Antoch, J. and Hanousek, J. (2000), 'Model selection and simplification using lattices.', CERGEEI Working Paper, Charles University in Prague, Czech Republic .

BCBS (2001), 'Working paper on the regulatory treatment of operational risk', Basel Committee on Banking Supervision, Basel, Switzerland .

BCBS (2004), 'Basel 2: International convergence of capital measurement and capital standards: a revised framework', Basel Committee on Banking Supervision, Basel, Switzerland .

BCBS (2010), 'Basel committee: Operational risk - supervisory guidelines for the advanced measurement approaches - consultative document', Basel Committee on Banking Supervision, Basel, Switzerland .

Bedford, T. and Cooke, R. (2002), 'Vines: A new graphical model for dependent random variables.', The Annals of Statistics 30(4), 1031-1068.

Berg, D. and Aas, K. (2009), 'Models for construction of multivariate dependence - a comparison study', The European Journal of Finance 15, 639-659.

Brechmann, E., Czado, C. and Aas, K. (2010), 'Truncated regular vines in high dimensions with applications to financial data., Submitted preprint. .

Capéraà, P., Fougères, A. and Genest, C. (2000), 'Bivariate distributions with given extreme value attractor.', Journal of Multivariate Analysis 72, 30-49.

Chernobai, A., Rachev, S. T. and Fabozzi, F. J. (2007), Operational Risk: A Guide to Basel II Capital Requirements, Models, and Analysis, John Wiley \& Sons.

Cruz, M. (2004), Operational Risk Modelling and Analysis, Risk Books, London. 
Di Clemente, A. and Romano, C. (2004), 'A copula-extreme value theory approach for modeling operational risk', Operational Risk Modelling and Analysis pp. 189-208.

Dissmann, J., Brechmann, E., Czado, C. and Kurowicka, D. (2011), 'Selecting and estimating regular vine copulae and application to financial returns.', Submitted preprint. .

Galambos, J. (1975), 'Order statistics of samples from multivariate distributions.', Amer. Statist. Assoc. 10, 674-680.

Gourier, E., Farkas, W. and Abbate, D. (2009), 'Operational risk quantification using extreme value theory and copulas: from theory to practice.', The Journal of Operational Risk 4.

Gudendorf, G. and Segers, J. (2010), Extreme-value copulas. In: Proceedings of the Workshop on Copula Theory and Its Applications held in Warsaw (editor: P. Jaworski), Springer Media, New York.

Guegan, D. and Hassani, B. (2011), 'Operational risk: A basel ii++ step before basel iii.', Working Paper, University Paris 1.

Guégan, D. and Hassani, B. K. (2009), 'A modified panjer algorithm for operational risk capital calculations', The Journal of Operational Risk 4, 53-72.

Guégan, D., Hassani, B. K. and Naud, C. (2011), 'An efficient threshold choice for the computation of operational risk capital', The Journal of Operational Risk 6, 3-19.

Guégan, D. and Maugis, P.-A. (2010), 'New prospects on vines.', Insurance Markets and Companies: Analyses and Actuarial Computations 1, 4-11.

Guégan, D. and Maugis, P.-A. (2011), 'An econometric study for vine copulas.', to appear in: International Journal of Economics and Finance .

Hüsler, J. and Reiss, R. (1989), 'Maxima of normal random vectors: Between independence and complete dependence.', Statistics $\&$ Probability Letters 7, 283-286.

Joe, H. (1996), 'Families of $m$-variate distributions with given margins and $\frac{m(m-1)}{2}$ bivariate dependence parameters.', Distributions with Fixed Marginals and Related Topics, Lecture NotesMonograph Series 28, 120-141. 
Joe, H. (1997), Multivariate models and dependence concepts., Monographs on Statistics and Applied Probability, Chapman and Hall, London.

Jorion, P. (2006), Value at Risk: The New Benchmark for Managing Financial Risk, McGrawHill Paris.

Kurowicka, D. and Cooke, R. M. (2004), 'Distribution - free continuous bayesian belief nets.', In Fourth International Conference on Mathematical Methods in Reliability Methodology and Practice, Santa Fe, New Mexico. .

Mendes, B., de Melo, E. and Nelsen, R. (2007), 'Robust fits for copula models', Comm. in Stat.: Sim. Comp 36, 997-1017.

Morillas, P. (2005), 'A method to obtain new copulas from a given one.', Metrika 61, 169-184.

Nelsen, R. (2006), An Introduction to Copulas., Springer Series in Statistics, Berlin, Germany.

Savu, C. and Trede, M. (2006), 'Hierarchical archimedean copulas.', Working Paper, University of Münster, Germany .

Silverman, B. W. (1986), Density Estimation for statistics and data analysis, Chapman and Hall/CRC.

Sklar, A. (1959), 'Fonctions de répartition à n dimensions et leurs marges', Publ. Inst. Stat. 8, 229-231.

Wand, M. P. and Jones, M. C. (1995), Kernel Smoothing, Chapman and Hall/CRC.

Weiss, G. (2010), 'Copula parameter estimation - numerical considerations and implications for risk management', Journal of Risk 13, 17-53. 